\title{
Discursos orientadores do uso do Design em práticas educativas
}

\author{
Bianca Martins (NUCAP | MPNTDE | UniCarioca | PUC-Rio) \\ Rita Couto (PUC-Rio)
}

\section{Resumo}

Este trabalho fundamenta-se na pesquisa de doutorado da autora ${ }^{1}$ e tem como intenção apresentar uma trama conceitual que oportuniza a construção do discurso do uso do Design nas práticas educativas e, em consequência, a concepção do Professor como um Designer de experiências de aprendizagem. Esmiuçam-se os conceitos de multirreferencialidade, multiplicidade e rizoma (ARDOINO, 1998; DELEUZE, 1994, 1997); a invenção de conceitos e concepções de problemas (DELEUZE, 1994, 1997 e RITTEL, 1973) e, ainda, a conexão entre estas noções e o campo da aprendizagem, trazendo uma discussão a respeito da aprendizagem inventiva (KASTRUP, 1999, 2005, 2008) para discutir a relevância do trabalho com problemas de design durante o processo de aprendizagem escolar (NORMAN, J., 2015; PINK, D., 2009; MARTINS, 2007; FONTOURA, A., 2002; HERNANDEZ, F, 1998; COUTO, R. 1997; ROYAL COLLEGE OF ART., 1979; ARCHER, B., 1979). Nesse sentido, discutem-se diferentes abordagens a respeito do currículo, sujeito, cultura e sociedade na intenção de encontrar o lugar do Design nas práticas educativas a partir de uma perspectiva que seja multiculturalista e interessada em valorizar o protagonismo dos sujeitos em relação à construção do conhecimento. Por fim, e para dar consistência ao discurso do Professor-Designer de Experiências de Aprendizagem, lança-se mão das discussões a respeito da Formação Docente e Cotidiano Escolar (ALVES, 2003). Assim, procura-se argumentar a relevância do trabalho com problemas de Design durante o processo de aprendizagem escolar e seus reflexos na formação docente. $\mathrm{O}$ artigo termina com as aproximações a uma Epistemologia para o uso do Design nas práticas educativas e, assim, busca-se argumentar os conceitos norteadores para colocá-la em prática, contribuindo para salientar a relevância do trabalho com problemas de Design durante o processo de aprendizagem escolar.

Palavras-chave: Design; práticas educativas; aprendizagem ativa; formação de professores; professor-fazedor.

\begin{abstract}
This work is based on the doctoral research of the author and aims to present a conceptual framework that allows the construction of the discourse of the use of Design in educational practices and, consequently, the conception of the Professor as a Designer of learning experiences. The concepts of multireferentiality, multiplicity and rhizome are explored (ARDOINO, 1998; DELEUZE, 1994, 1997); the invention of concepts and conceptions of problems (DELEUZE, 1994, 1997 and RITTEL, 1973) and also the connection between these notions and the field of learning, bringing a discussion about inventive learning (KASTRUP, 1999, 2005, 2008 ) to argue the relevance of work with design problems during the school learning process (NORMAN, J., 2015; PINK, D., 2009; MARTINS, 2007; FONTOURA, A., 2002; HERNANDEZ, F, 1998; COUTO, R. 1997; ROYAL COLLEGE OF ART, 1979; ARCHER, B., 1979). In this sense, different approaches to curriculum, subject, culture and society are discussed in order to find the place of Design in educational practices from a perspective that is multicultural and interested in valuing the protagonism of the subjects in relation to the construction of the knowledge. Finally, in order to give consistency to the discourse of the Teacher-Designer of Learning Experiences, the discussions about Teaching and Daily Life Formation (ALVES, 2003) are used. Thus, we try to argue the relevance of work with Design problems during the school learning process and its reflexes in teacher training. The article ends with the approaches to an Epistemology for use of Design in educational practices and, thus, seeks to argue the guiding concepts to put it into practice, contributing to highlight the relevance of the work with Design problems during the process of learning.
\end{abstract}

Keywords: Design, educational practices, active learning, teacher training, teacher-maker

1. Martins, Bianca Maria Rêgo. O Professor-Designer de experiências de aprendizagem: tecendo uma epistemologia para a inserção do Design na Escola. Orientadora: Rita Maria de Souza Couto; Co-orientador: Washington Dias Lessa. - 2016.188 f.; 30 cm Tese (doutorado) - Pontifícia Universidade Católica do Rio de Janeiro, Departamento de Artes e Design, 2016 


\section{Multirreferencialidade: uma perspectiva para compreender os fenômenos relacionados à educação}

A perspectiva do pensamento complexo de Edgar Morrin (1999; 2014) é oportuna aos estudos de Design por favorecer uma abordagem plural dos fenômenos do cotidiano. Contudo, este estudo apresenta o conceito da multirreferencialidade, que tem alguns pontos semelhantes ao discurso de Morrin, como sendo mais oportuno para o desenvolvimento de intervenções de Design relacionadas à educação. Vejamos por que o conceito é relevante para o âmbito da educação.

A multirreferencialidade é uma interpretação construída por Jacques Ardoino (1927-2015) para compreensão dos fenômenos sociais. Esta abordagem, à medida que pretende assegurar a complexidade de tais fenômenos, pressupõe a conjugação de uma série de elementos e saberes - de tal forma que eles não se reduzam uns aos outros - com a intenção de elaborar um tipo de conhecimento que se diferencia daquele que é concebido na ótica do cartesianismo e do positivismo. Sendo assim, a multirreferencialidade é apenas uma entre várias visões que fazem frente aos modelos científicos estruturados a partir do racionalismo cartesiano e do positivismo comteano.

Japiassu (1975), autor que se dedica ao estudo da Filosofia do Conhecimento, evidencia o contrassenso da busca de reconhecimento por parte das ciências humanas que o fazem querendo encontrar, contraditoriamente, sua legitimidade como ciências, apoiando-se em paradigmas então consagrados pelas ciências naturais em que a objetividade e a neutralidade eram almejadas em direção a um conhecimento positivo da realidade humana. Japiassu explicita, contudo, que atualmente parece claro que buscar nas ciências naturais os meios para garantir a legitimidade científica fez com que as ciências humanas assumissem os pressupostos das ciências naturais, incorporando perspectivas epistemológicas e metodológicas que não lhes são adequadas e que não possibilitam explicitar os fenômenos humanos em sua profundidade - em sua complexidade.

Japiassu (1975) esclarece, ainda, que, no decorrer da história do pensamento filosófico ocidental, a noção de uma realidade imutável, externa ao sujeito do conhecimento, tornou-se dominante. Nesse sentido, nos séculos XVII e XVIII, as duas perspectivas epistemológicas majoritárias, o racionalismo e o empirismo, apesar de todas as suas divergências, compartilhavam duas premissas básicas: 1. separação radical entre o sujeito e o objeto do conhecimento; e 2. uma relação linear e isomórfica do conhecimento com a realidade. Tais premissas são retomadas e radicalizadas, no século XIX, pela perspectiva positivista que se torna a referência epistemológica dominante nas ciências modernas. Vale ressaltar algumas características do positivismo que influenciaram sobremaneira o campo da educação e que serão problematizadas mais adiante:Separação excludente entre sujeito (pesquisador) e objeto de estudo;

- Subjetividade e afetividade consideradas de forma pejorativa, como fonte de erro;

- Supervalorização do método e desprezo pela teoria e interpretação: visão instrumentalista do conhecimento;

- Crença no empreendimento científico como algo neutro, objetivo;

- Método científico considerado de forma monolítica (o que varia são os objetos de estudo, o método de investigação é o mesmo para todas as ciências);

- Objetivos da ciência como uma descrição imparcial: predição e o controle sobre a realidade.

Conforme Japiassu, dentro dessa lógica, a complexidade, os processos fluídos são meras ilusões; a realidade seria ordenada por leis simples que regem os fenômenos físicos, biológicos e sociais, cuja descrição fidedigna pressupõe a adoção de instrumentos válidos, prescindindo do sujeito do conhecimento, bem como do contexto cultural em que se insere a atividade de pesquisa. Desse modo, a tentativa de eliminação tanto da dimensão contextual como da dimensão subjetiva acaba fortalecendo o mito da neutralidade científica e do controle dos pesquisadores em relação aos fenômenos estudados (JAPIASSU, 1975). 
Nesse sentido, a perspectiva multirreferencial adota um ponto de vista epistemológico diferente na construção do conhecimento a respeito dos fenômenos sociais, principalmente os educativos. Ela propõe abordar as questões anteriores tendo como objetivo estabelecer uma visão mais plural a respeito do humano a partir da conjugação de várias correntes teóricas. Tendo sido elaborada por Jacques Ardoino em meados da década de 1960, esta perspectiva põe em evidência a complexidade e a heterogeneidade que caracterizam as práticas sociais e, principalmente, as práticas educativas. Tal complexidade traz para aqueles que estão envolvidos com questões educacionais (alunos, professores, pedagogos, gestores, etc.) uma série de dificuldades de leitura e de compreensão a respeito de suas próprias práticas, o que pode desdobrar-se em dificuldades para a tomada de decisões (ARDOINO, 1998). Ardoino procura reconhecer o caráter plural destas práticas:

[...] no lugar de buscar um sistema explicativo unitário [...] as ciências humanas necessitam de explicações, ou de olhares, ou de óticas, de perspectivas plurais para dar conta um pouco melhor, ou um pouco menos mal, da complexidade dos objetos. (ARDOINO, 1998, p. 4)

Ou seja,

[...] para a análise multirreferencial das situações, das práticas, dos fenômenos e dos fatos educativos se propõe explicitamente uma leitura plural de tais objetos, sob diferentes ângulos e em função de sistemas de referências distintos, os quais não podem reduzir-se uns aos outros. Muito mais que uma posição metodológica, trata-se de uma decisão epistemológica. (Ardoino, 1995a, p. 7; grifo nosso)

Por isso, conforme Ardoino a multirreferencialidade esboça-se através dos conceitos de pluralidade e heterogeneidade. Vejamos.

\section{Pluralidade}

Segundo Ardoino (1998), a perspectiva da pluralidade contrapõe-se à questão da unidade sendo que esta última pode ser entendida sob diferentes aspectos. Por exemplo, e conforme a visão de Ardoino, um sistema educacional, como o brasileiro, que oferece uma formação integral do aluno, aponta para a formação de sujeitos que devem possuir as mesmas competências. Fica implícita aí a questão da repetição, da mesmice, ou seja, a pretensão de uma formação que oferece um caminho único. A repetição se desmembra, ainda, em duas perspectivas: a primeira diz respeito ao cumprimento das expectativas que professores e estudantes assumem uns dos outros; a segunda refere-se ao próprio processo de aprendizagem, cujo desdobramento revela-se nas eternas repetições do conteúdo aprendido, que são realizadas pelos alunos durante sua vida escolar.

Para fazer frente aos preceitos negativos da perspectiva da unidade, Ardoino (1998) argumenta que devemos considerar os espaços educativos em sua complexidade. A introdução dessa noção no âmbito educacional redimensiona-o, trazendo novas perspectivas para a pesquisa dos fenômenos que ali se estabelecem. Nesse ponto vale resgatar o pensamento de Morrin:

[...] uma viagem em busca de um modo de pensamento capaz de respeitar a multidimensionalidade, a riqueza, o mistério do real, e de saber que as determinações - cerebral, cultural, social, histórica - que se impõem a todo o pensamento co-determinam o objeto de conhecimento. É isso que eu designo por pensamento complexo. (MORIN, apud MARTINS, 2004, p. 24)

Cabe ressaltar que, para Morin, o paradigma da complexidade não produz nem determina a inteligibilidade. Considerar a complexidade relaciona-se muito mais a uma postura a ser adotada pelo pesquisador: ele pode incitar a estratégia/inteligência do sujeito pesquisador a considerar a complexidade da questão estudada (MORIN, apud MARTINS, 2004, p. 25).

Ou seja, para Morin, assim como para Ardoino (1998), a complexidade não está no objeto, mas no olhar utilizado pelo pesquisador para estudá-lo, ou seja, na maneira como ele aborda os fenômenos.

Portanto, para Ardoino, a educação abordada através da perspectiva multirreferencial seria

(...) uma função global, que atravessa o conjunto dos campos das ciências do homem e da sociedade, interessando tanto ao psicólogo como ao psicólogo social, ao economista, ao sociólogo, ao filósofo ou ao historiador etc. (ARDOINO, 1995, apud BARBOSA, p. 7). 
Nesse ponto vejo que é possível dizer que a perspectiva multirreferencial, à medida que postula que o conhecimento a respeito dos fenômenos educativos - considerando a complexidade destes últimos - deve ser construída através da conjugação de diversas disciplinas, inscreve-se num universo dialetizante, no qual o pensamento é elaborado em contínuo movimento, o que possibilitará a criação/construção do conhecimento.

Reconhecer a necessidade de um olhar múltiplo para a compreensão dos fenômenos educativos implica um rompimento com o pensamento linear, unitário e reducionista característico do paradigma da simplicidade e um olhar que privilegie o heterogêneo como ponto de partida para a construção do conhecimento. A partir da necessidade de lançar mão de uma perspectiva que conjugue conhecimentos dispersos, vejo uma oportunidade para o uso dos conhecimentos e procedimentos do Design para considerar os espaços educativos em sua complexidade. Dito de outro modo, o Design pode ser uma importante estratégia para favorecer a perspectiva multirreferencial na abordagem de problemas que envolvam ensino-aprendizagem.

\section{Heterogeneidade}

Assim como Morrin enfatiza a necessidade de conjugar noções complementares, concorrentes e antagônicas para a construção do conhecimento, Ardoino também salienta a relevância da heterogeneidade de pontos de vista, diferenças e contradições como um caminho fértil para a construção do conhecimento.

No âmbito dessa abordagem, a heterogeneidade deve ser entendida com base em duas perspectivas. A primeira está relacionada à conjugação de diversas disciplinas para o processo de elucidação dos fenômenos humanos. Quanto a este aspecto, pode-se dizer que o trabalho do pesquisador aproxima-se ao do bricoleur. Tal dificuldade leva o pesquisador a negociar com a realidade, buscando pedaços de teorias heterogêneas, estabelecendo um conhecimento plural da realidade (ARDOINO, 1998).

Contudo, Ardoino (1998) salienta que o desafio da abordagem multirreferencial é trabalhar com várias linguagens para a compreensão dos fenômenos sem, no entanto, homogeneizá-las, ou seja, sem reduzi-las umas às outras. O conhecimento produzido por essa postura seria, portanto, um conhecimento bricolado, tecido, etc. Nesse sentido, Ardoino enfatiza que a compreensão da realidade se efetiva apelando

a sistemas de referências, a grades de leitura diferentes (psicológicas, psicossociais, sociológicas). [...] O trabalho de análise consiste menos em tentar homogeneizá-las, ao preço de uma redução inevitável, que em procurar articulá-las, conjugá-las. (ARDOINO, 1995, Apud BARBOSA, p. 7).

Conforme Ardoino, a análise multirreferencial não tem como pretensão esgotar seu objeto de estudo. Analisar, nesse contexto, não se define mais por sua capacidade de recortar, de decompor, de dividir ou reduzir em elementos mais simples, porém por suas propriedades de compreensão, de acompanhamento dos fenômenos vivos e dinâmicos (ARDOINO, 1995).

Além disso, a abordagem multirreferencial - à medida que não se caracteriza como um movimento de decomposição ou redução de seus objetos - aceita a opacidade própria dos fenômenos humanos (o que pressupõe, consequentemente, o reconhecimento de sua complexidade).

\section{Sujeito implicado}

O segundo aspecto a destacar com relação ao papel da heterogeneidade na compreensão dos fenômenos humanos, conforme Ardoino (1998), diz respeito à questão da relação entre sujeito e objeto. A ciência que se desenvolveu durante a modernidade, como já comentado, tem como pressuposto um distanciamento entre sujeito e objeto fator que, idealmente, lhe garantiria a objetividade e a neutralidade do conhecimento.

A abordagem multirreferencial retoma essa discussão assumindo que o conhecimento se realiza precisamente ali onde a ciência cartesiana e positivista não o reconhece: na relação entre sujeito e objeto - na relação intersubjetiva.

Isto significa dizer que, no lugar de termos um objeto que se quer objetivo, teremos um objeto que é ao mesmo tempo sujeito (ARDOINO, 1998). 
Falando a respeito do ponto de vista do pesquisador, Ardoino considera que ele não domina/controla seu objeto, senão, está implicado com ele/nele. A implicação é entendida aqui como engajamento pessoal e coletivo do pesquisador na sua práxis científica, em função de sua história familiar e afetiva, de suas posições passadas e atuais nas relações de produção e de classe, e de seu projeto sociopolítico em ação, de tal modo que o investimento resultante de tudo isso seja parte integrante e dinâmica de toda atividade de conhecimento.

Portanto, a ideia de sujeito implicado sugere que o processo de construção do conhecimento não se desenvolve sob a égide exclusiva de uma determinada racionalidade. Pelo contrário, o conhecer se estabelece com base em várias outras perspectivas: das motivações mais profundas do pesquisador, de seus desejos, de suas projeções pessoais, das suas identificações, de sua trajetória pessoal, etc. Nesse sentido, podemos dizer que a relação entre sujeito e objeto propicia o desvelamento tanto do objeto como do sujeito.

\section{Intersubjetividades}

A partir da ideia de implicação, assume-se que o conhecimento produzido no âmbito da abordagem multirreferencial diz respeito a intersubjetividades, o que significa reconhecer que a produção de conhecimento relaciona-se a um processo de negociação entre as múltiplas referências que compõem o arranjo das representações de cada indivíduo envolvido no processo. Ou seja, o conhecimento se produz a partir da heterogeneidade implícita nas relações que se estabelecem no campo da pesquisa, projeto ou situação em questão.

A sutileza aqui apontada evidencia que a relação entre sujeito e objeto, entendida como um encontro intersubjetivo, requer o reconhecimento de dimensões que não estão relacionadas nem com os aspectos teóricos nem com os aspectos metodológicos utilizados na realização de pesquisas e/ou projetos. Tais dimensões estão circunscritas pela ordem do psíquico, do desejo, da vontade, o que implica o reconhecimento de afetos nem sempre identificáveis no cotidiano, mas que emergem durante a construção do conhecimento. Este fator fica bastante evidente nas entrevistas realizadas por Martins (2016) com professores e alunos dos cursos de Pedagogia e Design a respeito das relações afetivas em sala de aula.

Na perspectiva de Ardoino, a interação desencadeia jogos próprios das vontades, dos desejos, da angústia, das manifestações de uma vida inconsciente, de um funcionamento imaginário... (ARDOINO, 1995b, p. 19) que suscitam tantas estratégias, resistências, ambivalências, opacidades: expressões que permanecem ininteligíveis para um aparato racional. Tal situação, em função de sua complexidade, geralmente nos leva para os caminhos das incertezas e do inacabamento, condições impensáveis na ótica de uma epistemologia tradicional - cartesiana, positivista.

Por esses motivos, acredito que a multirreferencialidade traz abordagens férteis para tecer o discurso do uso do Design nas práticas educativas: uma perspectiva utilizada pelo professor/designer que se realiza através da pluralidade de conceitos e modos de articulá-los valorizando sua heterogeneidade; a postura do professor/designer como um sujeito implicado/ engajado ao seu objeto/planejamento acadêmico; o reconhecimento de que o sujeito se envolve, ou seja, se deixa afetar e também afeta o objeto trabalhado e, por fim, a evidência de que estes múltiplos relacionamentos e afetos manifestam as próprias incertezas do caminho trilhado.

\section{Aproximações entre a Multirreferencialidade de Ardoino e a Multiplicidade Deleuziana}

No momento em que chegamos ao ponto alto das contribuições de Ardoino para este estudo, parece-me oportuno conjugá-las a alguns conceitos Deleuzianos que trarão luz à costura do discurso basilar do uso do Design nas práticas educativas, uma vez que procuramos justificar sua pertinência como uma fértil estratégia articuladora de conhecimentos e fazeres na escola. Vale ressaltar que Deleuze (1925 -1995), filósofo reconhecido por um discurso inusitado e inconformado, não se debruçou propriamente sobre o campo da educação. No entanto, o vigor e consistência de seu discurso justificam aportes proveitosos para tal campo. Vejamos alguns pontos relevantes para este estudo.

Deleuze, ao seu modo, compartilhava de algumas perspectivas apontadas pela Multirreferencialidade de Ardoino. Assim como Ardoino, Deleuze (1994) concebe a realidade como múltipla, e não única. Ou seja, conforme Deleuze, a fragmentação do conhecimento, a divisão do saber em castas, só consiste em um problema para aqueles que possuem uma visão unitária do próprio conhecimento. Para estas pessoas, o conhecimento teria uma única matriz e para abarcá-lo seria necessário fragmentá-lo, ou seja, decompô-lo em partes menores. Segundo as ideias do autor, a partir da crítica a esta fragmentação excessiva surgiram propostas para rejuntar os conhecimentos. A interdisciplinaridade e a transdisciplinari- 
dade estariam ligadas a esta perspectiva. Nesta hipótese, o real é único, uma unidade, e para conhecê-lo devemos religar os saberes que um dia já estiveram unidos. Note-se que este religar, na visão de Deleuze, não acomodaria diferenças de perspectiva, de opiniões, e assimetrias. Por fim, tratar-se-ia de uma homogeneização ou uniformização.

A visão formulada por Deleuze para articular conhecimentos de distintas matrizes é a hipótese da multiplicidade. Para o autor, não há uma unidade perdida a ser rejuntada, pois nunca houve uma unidade. Temos a todo momento diferentes conhecimentos sendo produzidos. Em alguns momentos, surgem convergências e arranjos em que os conhecimentos se misturam. Para Deleuze, este emaranhado caracteriza o conceito de rizoma. Como se sabe, a metáfora do conhecimento do tipo rizoma - termo emprestado da botânica - esboça aqueles tipos de ramificações (conhecimentos) que se proliferam em múltiplas conexões sem um centro ou hierarquia e que podem acomodar encontros imprevisíveis. Cabe salientar que esta metáfora contrapõe-se à da árvore, em que há um tronco central, ou seja: o conhecimento hierárquico onde há um saber central que se desdobra em outros a ele subjugados.

Para contribuir à tessitura do discurso do uso do Design nas práticas educativas, a metáfora do rizoma parece-me muito proveitosa. Este conceito abre a oportunidade para pensar em uma aprendizagem rizomática como algo descentralizado e sem hierarquia. Com isso, quero dizer que é possível, a partir deste conceito, pensar em um percurso mais aberto do estudante pela trilha do conhecimento. Um fluxo que manifeste sem receio as incertezas/riscos que invariavelmente surgem pelo caminho. Um trajeto que permita ao estudante escolher os pontos de parada assim como a demora em cada um deles. Um caminho que seja conduzido pelo estudante, que se realize em parceria (implicado) com a construção de seus objetos do conhecimento e que valorize os parceiros (professores, colegas, família, etc.) e afetos que ali surgem.

Trazendo para esta perspectiva o papel do professor, a noção de aprendizagem baseada nas ideias de Deleuze evidencia, também, a ausência de hierarquia. Nesta perspectiva, a aprendizagem depende de uma articulação de signos e sentidos que às vezes estão alheios ao discurso do professor. Cabe a ele pensar em situações e apontar determinados elementos e ferramentas; contudo, a organização dos elementos e sua articulação com as ferramentas é trabalho do estudante.

Nesta visão de percurso rizomático da aprendizagem - diferente do tradicional em que já estão determinados um ponto de partida, um percurso e um ponto de chegada - não há um plano definido. Aqui existe uma oportunidade significativa para tecer mais um elemento do discurso do uso do Design nas práticas educativas. Conforme o mergulho na leitura de Deleuze (1994), trazemos a percepção da protagonismo do estudante em relação ao seu percurso de amadurecimento. Se, como já foi apontado, nesta abordagem, o estudante dispõe de uma série de elementos e ferramentas os quais organiza à sua maneira, vale também salientar que nesta perspectiva o estudante também atua na ressignificação dos problemas a serem abordados.

\section{Multirreferencialidade, o problema sensível e a aprendizagem inventiva}

Ainda conforme os achados trazidos do mergulho nas ideias de Deleuze, parece-me que vale a pena traçar uma ponte entre tais ideias e os tipos de problemas que o estudante pode abordar na perspectiva do uso do Design nas práticas educativas. Vejamos agora, então, a relação do uso do Design nas práticas educativas com a natureza dos problemas por ele abordados.

Navegando por águas Deleuzianas, parte-se da perspectiva de que a filosofia consiste na atividade de construção de conceitos (Deleuze; Guatarri, 1994). Esta é uma noção importante e radical, pois rompe com a visão anterior (inaugurada com a filosofia da antiguidade grega) de que a filosofia consiste em contemplação. Ou seja, para Deleuze e Guatarri pensar não é contemplar. Pensar é criar, e os conceitos são fabricados, criados, inventados.

Para Deleuze (1994), o conceito é um ato de pensamento que reúne uma série de elementos predispostos, organiza-os, e o resultado deste arranjo nos permite encarar um problema. Não é uma resposta; éuma maneira de organizar o pensamento para enfrentar um problema. Vale uma pausa para fazer uma conexão com Cross (2010) e Lawson (2011):

Conforme Cross (2010), os designers/projetistas manipulam códigos não-verbais da cultura material e traduzem-nos em mensagens através de objetos concretos e conceitos abstratos. Esse processo é potencializado pelo raciocínio do designer, que é focado na busca de soluções. Além disso, o processo de Design desenvolve nos estudantes a habilidade para lidar com uma classe particular de problemas, caracterizada pelos problemas complexos, que trabalham com a incerteza, com múltiplas dimensões e implicações, mal definidos e/ou mal estruturados. Esta classe de problemas é nomeada de wicked problems (RITTEL, 1973) ${ }^{1}$. Isso nos leva a acreditar que a natureza dos wicked problems emerge das questões cotidianas, ou seja, são situações indesejadas ordinárias e próximas das questões e decisões enfrentadas pelas pessoas no dia a dia.

1. Wicked problems são problemas incompletos, contraditórios e com requisitos mutáveis, as soluções para eles são frequentemente difíceis de se reconhecer por conta de sua interdependência. Foi conceitualmente sugerido por Horst Rittel (1973). 
Aprender a abordar de forma eficiente problemas complexos (wicked problems) exige a formação de um sujeito hábil a compreender a natureza deles, com competência para identificar suas múltiplas facetas e suas diferenças para outras classes de problemas. Ou seja, para enfrentar os wicked problems mencionados por Cross, seria necessário partir de uma abordagem multirreferencial (Ardoino) e/ou encarar que a realidade/conhecimento não é uniforme e sim múltipla (Deleuze).

Corroborando com a perspectiva de que os wicked problems exigem uma abordagem pautada na multirreferencialidade, saliento as ideias de Lawson (2011) no ponto em que o autor esclarece que a ação de projetar exige um grande leque de habilidades. Para tal, os projetistas precisam aprender a entender os problemas que outras pessoas consideram complexos e difíceis e devem, ainda, oferecer a elas boas soluções (Lawson, 2011: 36).

Chegamos até aqui costurando a noção de que o uso do Design nas práticas educativas contribui para construir com os estudantes a perspectiva de que o conhecimento é multirreferencial e a realidade é múltipla. Mais além, aprender a projetar (ou aprender projetando) favorece o desenvolvimento de um processo mental complexo e sofisticado, capaz de manipular muitos tipos de informações, misturando-os num conjunto coerente de ideias, e, finalmente, gerando alguma concretização dessas ideias. Fazendo novamente uma ponte com as ideias de Deleuze/Ardoino: aprender projetando seria uma maneira de organizar o pensamento para enfrentar um problema multirreferencial.

Contudo, para Deleuze (1994), o problema não é algo racional (como algo matemático); o problema é sensível, ou seja, sentido antes de ser construído racionalmente. Para o autor, o problema não é do domínio do entendimento, senão da sensibilidade. Esta sensibilidade nos mobilizaria e nos forçaria a pensar. Para Deleuze, este problema sensível nos instiga a criar conceitos ${ }^{2}$.

O conceito Deleuziano de que o problema sensível nos instiga a criar conceitos também é oportuno para tecer a sustentação do aprender projetando. Aqui encontro uma conveniente conexão com os estudos de Kastrup (2012) - que também trabalha com as ideias de Deleuze, ressignificando-as para o contexto da psicologia e do ensino da Arte - quanto ao aspecto da aprendizagem inventiva. Nesta abordagem, a aprendizagem implica não só a solução de problemas: é também, senão, um processo de invenção de problemas. Conforme Kastrup, o aprendizado envolve experiências de problematização que forçam a pensar. Segundo a autora,

A arte não transmite informação, mas provoca perturbação. Ela mobiliza uma atenção de qualidade distinta daquela envolvida na execução de uma tarefa. O aprendizado da arte não se esgota na aquisição de respostas e de regras. A aprendizageminventiva possui duas características. Em primeiro lugar, ela não se esgota na solução de problemas, mas inclui a invenção de problemas. Em segundo lugar, ela não é um processo de adaptação ao mundo externo, mas implica na invenção do próprio mundo. O inacabamento é sua marca, o que aponta para um processo de aprendizagem permanente, mas também de desaprendizagem permanente (KASTRUP, 2012, pg. 4).

Esta invenção de problemas defendida por Kastrup pode ser entendida como uma aprendizagem da problematização, na qual se enfatiza que os estudantes têm direito a identificar seus próprios problemas a abordar. Isso implica uma competência sutil: saber identificar problemas para resolver. Logo, chegamos novamente à questão da autonomia na aprendizagem.

Outra abordagem relevante no discurso de Kastrup que corrobora a concepção do aprender projetando é a importância atribuída ao plano dos afetos, do se deixar afetar, durante a aprendizagem/investigação - assim como o problema sensivel de Deleuze, o sujeito implicado e as intersubjetividades em Ardoino. A autora salienta que qualquer experiência estética caracteriza-se por posturas de estranhamento e surpresa que deslocam o eu e mobilizam uma atenção aberta ao plano dos afetos. Não se ensina transmitindo informações. O professor atua como um dispositivo por onde circulam afetos. Ele não é professor porque detém um saber, mas porque possui um savoir-faire com esta dimensão da experiência (KASTRUP, 2012, pg. 4).

\section{O Professor como um Designer de Experiências de Aprendizagem}

É possível dizer que os professores que deixam marcas positivas em nossa memória são sujeitos que trabalham com muita criatividade em seu ofício. A criatividade à qual me refiro é aquela discutida por Cross (2010) e por Gardner (1999): um certo tipo de inteligência desenvolvida em uma área específica. Há docentes que têm desenvoltura interpessoal e sabem conectar os diversos perfis de aluno para o conhecimento que está sendo construído. Há outro tipo que prepara estratégias

2. Nesta perspectiva de que o problema sensível nos instiga a criar conceitos pode-se traçar um paralelos férteis com as perspectiva de Ardoino do sujeito implicado e das intersubjetividades durante o processo de investigação sob a perspectiva da multirreferencialidade e também com a perspectiva do Design em Parceria. 
e materiais que instigam a atenção do aluno. Outros, ainda, possuem um carisma e empatia tal que encantam ao comentar qualquer assunto. Mas onde está o Design nisso tudo? A concepção do Professor como um Designer de experiências não seria uma estratégia argumentativa que considera que o Design está em tudo? Neste momento, a intenção é lançar luz sobre esta concepção.

Martins (2016) comenta que durante uma roda de conversas com alunos de pedagogia de uma universidade pública do Rio de Janeiro a respeito da própria Formação de Professores, estes estudantes demonstraram aborrecimento em suas falas com a tal pedagogia da Pedagogia, ou seja, estavam descontentes com o modo como a maioria dos professores da pedagogia dinamizava suas aulas. Segundo esses estudantes, a maior parte dos professores fala em uma educação transformadora, transgressora, formas inovadoras de avaliação, etc. Porém, suas próprias aulas seriam absolutamente tradicionais. Conforme estes estudantes, a tradição perpassa também os espaços de aprendizagem da pedagogia: salas com cadeiras enfileiradas; estratégias e materiais didáticos fortemente baseados em leitura, slides e discussões sobre temas e autores muito distantes da realidade dos alunos; ênfase numa postura passiva (bancária) por parte dos estudantes; e avaliações formativas com base em memorização das ideias contidas nos textos. Martins (2016) constata ainda, a partir de entrevistas com outros estudantes de um curso de Pedagogia de uma instituição privada, que existe a queixa de que os professores desta instituição podavam qualquer iniciativa transformadora, pois, segundo estes docentes, não existiria espaço para isso nas escolas brasileiras.

Ora, não é a mudança na Educação o embrião de uma mudança na sociedade? Como conceber, então, que os próprios professores das Pedagogias e Licenciaturas sejam os vetores de uma fala conservadora e, por que não dizer, acovardada a respeito de estratégias didáticas mais atraentes? Como conceber, ainda, que uma Formação de Professores de uma das instituições melhor avaliadas no Brasil, em pleno século XXI, ainda possua um quadro docente que em sua maioria, apesar de falar em transformações, ainda faça uso de práticas tão ultrapassadas de ensino aprendizagem?

Bem, entre realidade e utopia, sigo procurando o que é alcançável. Martins (2016), a partir de entrevistas com professores e alunos dos cursos de Design e Pedagogia, tentou entender como um professor pode fazer diferença para os alunos. Vimos - e sabemos ser fato no nosso cotidiano docente - que nem todos os professores têm motivação para fazer diferença. Seja por questões financeiras, condições de trabalho, valorização da profissão, empatia com estudantes, dentre outros motivos. Mas, a partir da investigação de Martins (2016), é possível perceber que o professor-fazedor é aquele sujeito que tem vontade de fazer sentido para seus estudantes; aquele que afeta, ou seja, trabalha com emoção, paixão, e se permite afetar pelos ânimos e conhecimentos construídos. Alguém que sabe que a incerteza e o improviso fazem parte do conhecimento e por isso alguém que se permite errar.

É justamente neste ponto, e pelo conhecimento tecido nesta pesquisa a partir de múltiplas referências - literatura específica, estudo de casos, vivências, entrevistas, etc. (MARTINS, 2016), onde vejo que há uma oportunidade latente para a inserção dos conhecimentos e procedimentos do Design na Formação de Professores. Entendo que, desse modo, trabalhando com Design no espaço-tempo em que o sujeito-professor está sendo formado, há maiores oportunidades para sensibilizar este docente para uma ação pedagógica mais significativa para o estudante. Contudo, como veremos adiante, um mergulho nos conhecimentos e procedimentos do uso do Design como prática educativa não se limita, somente, ao espaço-tempo da Formação de Professores.

De modo sucinto - pois abordaremos amiúde esta questão no próximo item -, o uso do Design nas práticas educativas consistiria, então, na prática de ações de Design a partir do desenvolvimento de objetos, comunicações ou estratégias, conectando conhecimentos de áreas muito dispersas (multirreferencialidade) na intenção de propor uma solução para um problema cotidiano identificado pelo aprendente (problematização, wicked problems, tema significativo, aprendizagem inventiva) e cuja solução precise atender às demandas de outro sujeito (empatia, testagem de soluções).

Resgatando um conceito apresentado por Meredict Davis (1997), podemos dizer que essa proposta de aprender projetando usa o Design como um catalisador da aprendizagem e conecta, ainda, diferentes dimensões do saber (multirreferencialidade). 
A partir do conceito de Atelierista - sujeito articulador das propostas criativas e didáticas das Escolas Réggio Emília na Itália (RINALDI, C, 2012; GIACOPINI, B. E.; BASSI, L, 2014; MARTINS, 2016) - vislumbrei a concepção de um suposto Designerista: profissional que seria responsável pela proposição e supervisão dos projetos baseados em Design dentro de uma escola. No entanto, diferente da dimensão do Designerista, cuja atuação exigiria uma formação específica e alterações na legislação para que sua atuação fosse regulamentada nas escolas, a noção do uso do Design nas práticas educativas exalta a capacidade do próprio professor ser este Designer de Experiências de Aprendizagem. Isso implica um processo de empoderamento do professor: ele passa a ser concebido como alguém que precisa saber gerenciar projetos e lidar com expressões em múltiplas linguagens - questões da contemporaneidade.

Mas como qualificar este professor para que possa ter desenvoltura para trabalhar nesta perspectiva?

Para comentar a respeito de uma provável trajetória de formação deste sujeito-professor, escolhi trazer o discurso de Nilda Alves, educadora e pesquisadora dos temas Formação Docente e Cotidiano Escolar. Alves (2003) desenvolve um sutil pensamento a respeito dos processos necessários para o desenvolvimento de ações nos cotidianos escolares ${ }^{1}$, lugar em que se realiza a prática docente em questão. Antes de mais nada, destaco que a concepção de Alves em muito contribui para corroborar a visão de que é nos desafios do cotidiano que aprendemos a qualificar nosso trabalho. O cotidiano escolar é multirreferencial e muito mais rico do que as abstrações propostas em exercícios ou simulações em sala de aula na Formação de Professores.

O discurso da Alves (2003) oportuniza a perspectiva de enxergar o cotidiano como tema a problematizar. Para a autora, o estudo do cotidiano escolar refere-se a questionar como se construiu um olhar hegemônico e depreciativo a respeito das escolas e as práticas docentes. De certa forma é uma abordagem crítica aos recursos discursivos que canonizam ideias associadas à classificação, generalização e hierarquização, ideias estas que invisibilizam sujeitos, saberes, produções e práticas não hegemônicas nos cotidianos. Para Alves (2003), é necessário encontrar outras estratégias de campo que abordem a complexidade dos cotidianos, buscando captar saberes, valores, sentimentos e modos de interação específicos de cada espaço-tempo social, respeitando-lhe o modo de ser e com ele dialogando.

Considero que a proposta do Professor como um Designer de Experiências de Aprendizagem imbrica e favorece a noção de que este docente atua como um articulador das dimensões do cotidiano escolar, concebendo, então, os estudantes (seus conflitos, subjetividades e saberes), o meio (sala de aula, espaços, mobiliário, materiais e insumos, recursos tecnológicos, etc.) e o conhecimento como ingredientes a conjugar nessa proposta de ação. Portanto, isso significa que práticas do Design ajudam a qualificar a docência, pois esta estratégia favorece a proposta de Alves, colocando o professor em evidência como um articulador da complexidade de saberes, valores, sentimentos e modos de interação de cada espaço-tempo social.

Mas qual seria, então, o lugar/momento adequado para qualificar essa docência? Sobre este aspecto, Alves convida a questionar a respeito do espaço-tempo da Formação de Professores. A autora comenta que a formação do professor não se dá exclusivamente no âmbito da formação acadêmica; ela é uma tessitura em rede, e essa rede faz alusão clara às ideias de Deleuze a respeito do rizoma. Para Alves (2003), a formação de professores se dá em redes educativas em múltiplos contextos que extrapolam o contexto da formação acadêmica e remetem a espaços-tempos que podem também antecedê-la. Alves (2003) também põe em evidência que estes contextos possuem práticas-teorias - conceito que imbrica essas duas dimensões do conhecimento - que podem ser os das práticas-teorias da formação acadêmica, práticas-teorias das pedagogias cotidianas, práticas-teorias das políticas de governo, práticas-teorias coletivas dos movimentos sociais, práticas-teorias das pesquisas em educação, práticas-teorias de produção e usos de mídias, práticas-teorias de vivências nas cidades. Ou seja, a formação do professor se dá no cotidiano e em suas diversas oportunidades de questionar e materializar saberes, ou como coloca Alves, oportunidades de fazer-pensar-fazer o que é ser docente.

Portanto, a formação de professores, nesta abordagem, consiste em um processo que ocorre de modo não-linear, e onde a interação entre contextos e sujeitos oportuniza a incorporação e significação de conhecimentos e valores, permitindo que esses sujeitos ressinifiquem a si próprios e também suas práticas.

O discurso de Alves (2003) a respeito da formação docente apresenta, ainda, outras várias sinergias com a proposta do Professor-Designer de Experiências de Aprendizagem. Esmiuçando a questão da aprendizagem como experiência através dos cinco sentidos que vejo como necessária a esta abordagem pedagógica, a autora faz um interessante ensaio, que considero importante comentar, sobre os movimentos necessários para fazer-pensar-fazer os mergulhos no cotidiano escolar. Nele Alves propõe, por exemplo - e para exaltar a importância da experiência através dos cinco sentidos, em oposição à primazia

4. A autora é reconhecida por seus neologismos juntando palavras. Para Nilda novas ideias implicam em novos conceitos. Por isso, a autora conecta termos que considera inseparáveis e que, escritos dessa forma, implicam em novos conceitos mais adequados que os anteriores para lançar luz aos assuntos em pauta. 
do sentido da visão (ver para crer) - mergulhar na prática docente utilizando-se de todos os sentidos, nomeando o primeiro movimento de sentimento do mundo. Quanto a esse sentimento do mundo, Alves comenta que o professor precisa

mergulhar inteiramente em uma determinada realidade buscando referências de sons, sendo capaz de engolir sentindo a variedade de gostos, caminhar tocando coisas e pessoas e se deixando tocar por elas, cheirando os cheiros que a realidade vai colocando a cada ponto do caminho diário. (ALVES, 2003, p.5)

O segundo movimento, conforme Alves, é o de questionar as teorias, conhecimentos e noções herdados da Modernidade e que seriam hoje, além de um apoio, também um limite que precisa ser questionado se temos como intenção compreender a tessitura dos conhecimentos cotidianos. A necessidade deste questionamento também pode ser encontrada nos discursos de Morrin, Ardoino, Deleuze, etc., que abordamos acima. Alves nomeia esse segundo movimento, que busca compreender como limite o que era habitualmente visto como apoio, como de virar de ponta cabeça.

O terceiro movimento fala a respeito da necessidade de ampliação do que é entendido como fonte, discutindo os modos de lidar com a diversidade, a diferença e a heterogeneidade dos cotidianos e de seus praticantes e modos como ambos se relacionam. Esse movimento diz respeito também à importância de conceber como fonte as diferentes linguagens como falas, imagens, vídeos, etc. Alves define esse terceiro movimento como a necessidade de beber em todas as fontes.

O quarto movimento aborda a linguagem necessária para comunicar novas preocupações, novos problemas, novos fatos e novos achados. Conforme Alves, é indispensável uma nova maneira de escrever que chegue de forma sensível aos praticantes dos cotidianos onde eles se vejam incluídos. Este movimento foi nomeado por Alves como narrar a vida e literaturizar a ciência.

Na caracterização do último movimento, o quinto, Alves põe em evidência o sujeito-protagonista que atua e constrói seu cotidiano. A autora comenta que o que de fato interessa nas estratégias pedagógicas nos/dos/com os cotidianos escolares são as pessoas, ou seja, os praticantes/pensantes do cotidiano. Para abordar essa dimensão, Alves traz uma fala de Souza Dias, que por sua vez é um apreciador de Deleuze, autor cuja importância cresceu sobremaneira no decorrer desse estudo com os acontecimentos de uma vida, as coisas, gentes, livros, ideias e experiências que consubstanciam em nós, insensivelmente até com os nossos devires e que traçam a nossa autêntica individualidade. E faz-se com tudo isso não enquanto vivências subjetivas, percepções, afeições e opiniões de um eu, mas como singularidades pré-individuais, infinitivos suprapessoais e, como tal, partilháveis, 'comunicáveis', correntes de vida transmissíveis. Escreve-se, pinta-se, compõe-se sempre com a multiplicidade que há em nós, que cada um de nós é, o sujeito criador é sempre coletivo, o nome do autor sempre a assinatura de uma sociedade anônima (SOUSA DIAS, 1995, p.104-105, apud ALVES, 2003, p. 7).

O fazer-pensar-fazer de Alves através de uma ação pedagógica que leve em conta os cinco movimentos apresentados acima possibilita falar de uma formação do Professor-Designer de experiências de aprendizagem que tenha como premissa epistemológica, política e metodológica que o sentir, o ser, o fazer e o pensar não se separam.

Por isso, penso que qualificar o professor para trabalhar nessa perspectiva do Design como prática educativa é tarefa que pode ser desempenhada em espaços-tempos, para citar Alves, bem diferentes conforme a necessidade. Imagino que, conforme essa necessidade, seja possível trabalhá-la através de uma formação continuada dentro das escolas ou até mesmo configurar uma especialização docente. Contudo, imagino que levar a abordagem do Design como prática educativa às graduações de Pedagogia e Licenciatura seja muito oportuno por todos os motivos que venho argumentando.

Por isso, de forma bastante ampla, imagino que esses encontros - que podem ser realizados através de disciplinas da pedagogia, ou oficinas, ou em uma formação continuada, ou em uma especialização, dentre outros - consistem em momentos onde o professor é estimulado a se colocar no papel de aluno que, ao abordar uma situação real indesejada, precisa imaginar, projetar e testar uma solução problematizando o contexto e público nela envolvidos.

\section{Considerações finais: aproximações a uma epistemologia para o uso do Design como prática educativa}

Uma vez tendo finalizado o item anterior justificando que a qualificação do Professor-Designer de Experiências de Aprendizagem pode ocorrer em espaços-tempos bastante variados conforme a necessidade, venho agora delinear alguns pontos importantes a serem abordados para dar consistência ao discurso das dimensões do Design como prática educativa. 
Considero que estes pontos importantes podem ser concebidos até mesmo como uma epistemologia, pois são abordagens/ concepções, ou seja, são modos de encarar ou então perspectivas específicas a respeito do conhecimento, dos tipos de problemas, dos contextos sociocultural e ambiental, dos estudantes e dos professores que caracterizam o discurso do Design como prática educativa. Mas, parece-me mais apropriado conceber esta questão como uma busca que nunca cessa, pois que o conhecimento, do modo como foi trabalhado nesta pesquisa, é algo sempre em construção, inacabado, e reside neste aspecto um eterno convite à participação dos sujeitos nesta ação construtiva.

Por este motivo, uma aproximação à epistemologia do uso do Design como prática educativa parte da perspectiva pós-Moderna, pós-estruturalista e pós-Colonialista da hibridização de linguagens, subjetividades, relações de poder e políticas de representação e onde, por isso, é necessário tecer, imbricar e articular saberes de diferentes dimensões e levar em consideração as novas modalidades de aprendizagem em redes, a autoria, a polifonia, a criatividade, aprendizagem inventiva, a aprendizagem tendo como ponto de partida as situações reais do cotidiano vivenciadas pelo estudante, a cooperação e as relações afetivas.

Por outro lado, uma aproximação à epistemologia do uso do Design como prática educativa compreende o Design como um modo de problematizar (Design Thinking), ou seja, uma forma de abordar situações complexas (wicked problems) buscando soluções que integram elementos visuais e estruturais de forma inovadora e que proporcionem um diferencial qualitativo em relação a uma situação prévia.

Também, uma aproximação à epistemologia do uso do Design como prática educativa significa conceber a comunidade ao redor da escola como um livro-texto onde a natureza complexa dos problemas demanda um conhecimento interdisciplinar que incorpore também o conhecimento já construído por esta própria comunidade.

Uma aproximação à epistemologia do uso do Design como prática educativa constrói-se através de uma perspectiva multidimensional. Eis algumas dimensões identificadas:

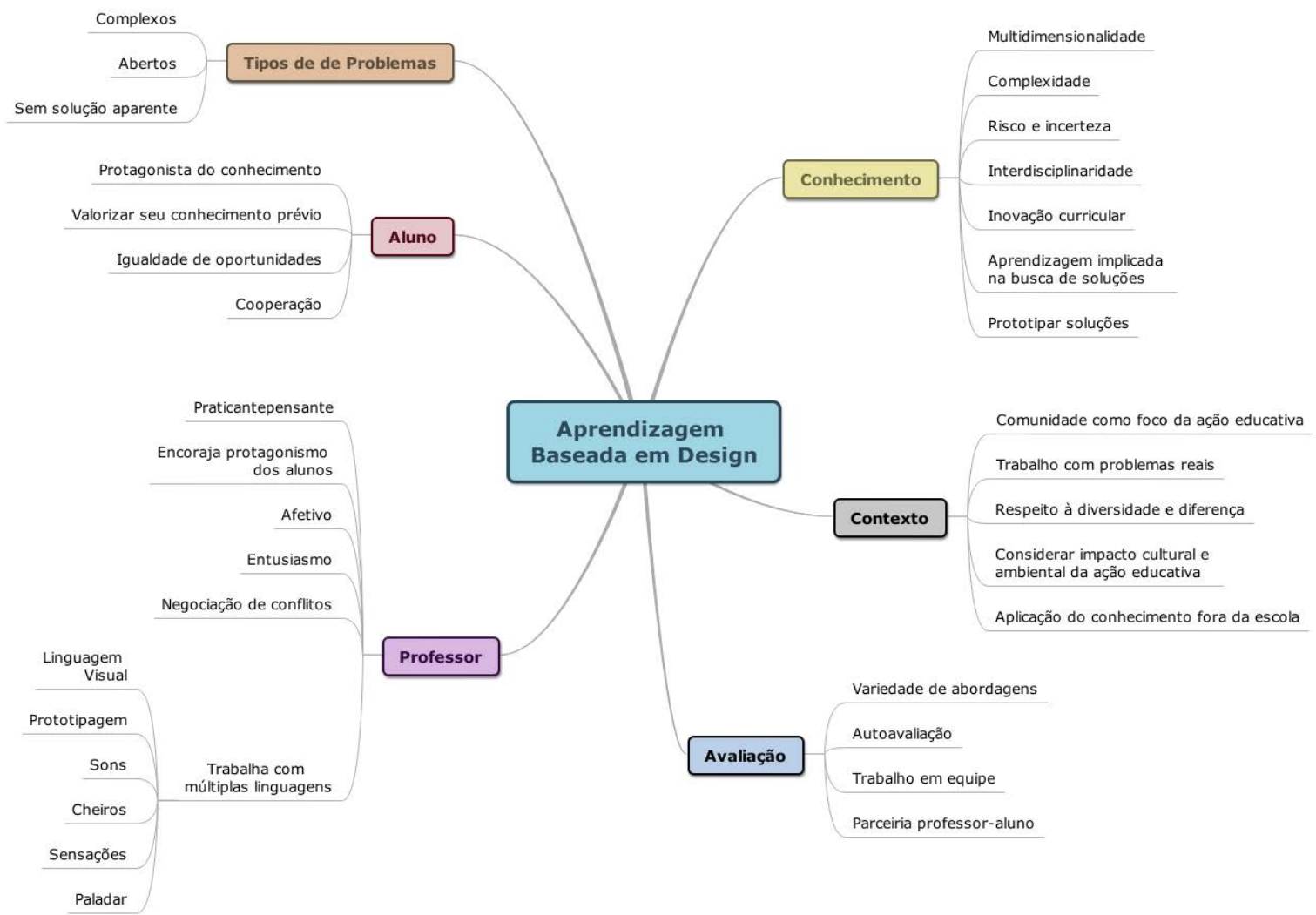

Figura1: Mapa conceitual da aproximação à epistemologia da Aprendizagem Baseada em Design.

Por fim, insisto em que o uso do Design como prática educativa consiste em uma postura, visão de mundo e política para ação que vê no desenvolvimento de projetos de Design a oportunidade para uma aprendizagem que articule saberes, procedimentos e afetos favorecendo uma prática educativa mais instigante e atrativa para os alunos e docentes. 


\section{Referências Bibliográficas}

ALVES, N. Sobre os movimentos das pesquisas nos/dos/com os cotidianos. In: TEIAS: Rio de Janeiro, ano 4, n 7-8, jan/dez 2003. ARCHER, Bruce, Design as a Discipline, Design Studies, Vol 1, No 1, July 1979, pp.17-20.

ARDOINO, J. Abordagem Multirreferencial (plural) das situações educativas e formativas. In: BARBOSA, Joaquim (Coord.). Multirreferencialidade nas ciências e na educação. Trad. Rosângela B. de Camargo. São Carlos, SP: EdUFSCar, 1998. p. 24-41.

ARDOINO, J. Prefácio. In: BARBOSA, Joaquim (Coord.). Multirreferencialidade nas ciências e na educação. Tradução Sidney Barbosa. São Carlos, SP: EdUFSCar, 1998. P.14-17.

BARBOSA, Joaquim.; MACEDO, Roberto.; BORBA, Sergio (org). Jacques Ardoino \& a Educação. Belo Horizonte: Autêntica Editora, 2012.

BURNETTE, C. IDESIGN - 7 ways of Design Thinking, A teacher resource. Disponível em: Acesso em: abril de 2014.

COUTO, R. Movimento Interdisciplinar de designers Brasileiros em Busca de Educação Avançada. Rio de Janeiro, 1997. 220p. Tese de Doutorado Departamento de Educação, PUC-Rio.

CROSS, N. Designerly ways of knowing, Springer-Verlag, London, 2006

CROSS, N. Design Thinking: Understanding How Designers Think and Work. Oxford: Berg Publishers, 2011.

DAVIS, Meredith. et al. Design as a Catalyst for Learning. Virginia: ASCD, 1997.

Education by Design. In: Arts Education Policy Review. Vol. 105, No. 5, May/June 2004.

DELEUZE, G. O que é a Filosofia? Rio de Janeiro: Ed. 34, 1994.

DELEUZE, Gilles e GUATTARI, Félix. Mil Platôs. Capitalismo e Esquizofrenia. Rio de Janeiro: Editora 34, 1995-1997. 715 pp.

FAZENDA, Ivani C. A. O que é Interdisciplinaridade? São Paulo: Cortez, 2008.

. (org.) Interdisciplinaridade na formação de professores. Canoas: Ed. Ulbra, 2006.

FONTOURA, A. M. Tese de doutorado. EdaDe: a educação de crianças e jovens através do Design. Orientadora: Alice Theresinha Cybis Pereira. Florianópolis: [s.n.], 2002

FRANCO, M. Pedagogia da pesquisa-ação. In: Educação e Pesquisa, São Paulo, v. 31, n. n.3, p. 483-502, 2005.182

GALLO, Sílvio. Deleuze \& a Educação. Belo Horizonte: Autêntica Editora, 2003.

GIACOPINI, B. E.; BASSI, L. Reggio Emília: uma experiência inspiradora. Vitória Faria e Alex Criado. In: Revista Criança do Professor de Educação Infantil, Brasília: SEB/MEC, 43, ago. 2007, p. 5-8. Disponível em: <http://www.oei.es/noticias/IMG/pdf/revista_crianca43.pdf>.. Acesso em: 10 nov. 2014.

HERNANDEZ, F.; VENTURA, M. A organização do currículo por projetos de trabalho. Porto Alegre: Artmed, 1998.

JAPIASSU, H., MARCONDES, D. Dicionário Básico de Filosofia. Rio de janeiro: Jorge Zahar, 2001.

KASTRUP, V. A invenção de si e do mundo: uma introdução do tempo e do coletivo nos estudos da cognição. São Paulo: Papirus, 1999.

KASTRUP, V., TEDESCO, S., PASSOS, E. Políticas da cognição. Porto Alegre: Sulina, 2008.

KASTRUP, V. Políticas cognitivas na formação do professor e o problema do devir-mestre. In: Educ. Soc., Campinas, vol. 26, n. 93, p. 1273-1288, Set./ Dez. 2005.

KNOLL, M. D. The project method: its vocational education origin and development. In: Journal of Industrial Teacher Education, v. 34, n. 5, Spring 1997. Disponível em: Acesso em: 25 jul. 2004.

LAWSON, B. Como arquitetos e designers pensam. São Paulo: Oficina de textos, 2011.

LIBÂNEO, J. Adeus professor, adeus, professora? Novas exigências educacionais e profissão docente. São Paulo: Cortez, 2001.

LIBÂNEO, J. Pedagogia e pedagogo para quê? São Paulo: Cortez, 2005.

MARTINS, Bianca. Design da informação de situações de utilidade pública. Orientadora: Rita Maria de Souza Couto. Rio de Janeiro: PUC-Rio, Departamento de Artes \& Design, 2007. 183

MARTINS, João Batista. Contribuições epistemológicas da abordagem multirreferencial para a compreensão dos fenômenos educacionais. Rev. Bras. Educ., Ago 2004, no.26, ISSN 1413-2478

MATURANA, H., VARELA, Francisco. De máquinas e seres vivos. Autopoiese, a Organização do Vivo. Porto Alegre: Artes Médicas, 1997.

MEYERS, C.; JONES, Thomas B. Promoting active learning. San Francisco: Jossey Bass, 1993.

MORAES, Maria Cândida O paradigma educacional emergente. Campinas, SP: Papirus, 2005.

MORIN, E. Introdução ao pensamento complexo. 3. ed. Porto Alegre: Sulina, 2007 pa-América, 1999.

MORIN. E. 2014. Entrevista ao Jornal O Globo. Agosto, 2014.

NORMAN, J. Design as a framework for innovative thinking and learning: how can Design thinking reform education. IDATER 2000 Conference, Loughborough: Loughborough University, 2001. OECD. Education Policy Outlook 2015 - Making Reforms Happen. OECD, 2015.

PINK, Daniel. The puzzle of motivation. In: TED Global, 2009.

RAIZEN, S. et al. Technology education in the classroom. Understanding the designed world. San Francisco: Jossey-Bass Publishers, 1995.

RIBEIRO, R. de C. A aprendizagem baseada em problemas (PBL): uma implementação na educação em engenharia. Tese (Doutorado) - UFSC, Florianópolis, 2005 
RITTEL H., WEBBER M. Dilemmas in a General Theory of Planning. Amsterdam: Elsevier Scientific Publishing Company, 1973.

RINALDI, C. Diálogos com Reggio Emilia: escutar, investigar e aprender. São Paulo: Paz e Terra, 2012.

ROYAL COLLEGE OF ART. Design in General Education. London: Royal College of Art, 1979.

SIMON, H. The science of the artificial, Cambridge (MA.): MIT Press, 1969.

UNESCO. Fundamentos da nova educação. Brasília: UNESCO, 2013. Disponível em: Acesso em: abril de 2014.

\section{Contato das autoras}

Bianca Martins | bmartins@unicarioca.edu.br

Rita Couto | ricouto@puc-rio.br 